\title{
Phylogeny of Fast-Growing Soybean-Nodulating Rhizobia Supports Synonymy of Sinorhizobium and Rhizobium and Assignment to Rhizobium fredii
}

\author{
B. D. W. JARVIS, ${ }^{1 *}$ H. L. DOWNER, ${ }^{2}$ AND J. P. W. YOUNG ${ }^{2}$ \\ Department of Microbiology and Genetics, Massey University, Palmerston North, \\ New Zealand, ${ }^{1}$ and John Innes Institute, Norwich NR4 7 UH, England ${ }^{2}$
}

\begin{abstract}
We determined the sequences for a 260 -base segment amplified by the polymerase chain reaction (corresponding to positions 44 to 337 in the Escherichia coli 16S rRNA sequence) from seven strains of fast-growing soybean-nodulating rhizobia (including the type strains of Rhizobium fredii chemovar fredii, Rhizobium fredii chemovar siensis, Sinorhizobium fredii, and Sinorhizobium xinjiangensis) and broad-hostrange Rhizobium sp. strain NGR 234. These sequences were compared with the corresponding previously published sequences of Rhizobium leguminosarum, Rhizobium meliloti, Agrobacterium tumefaciens, Azorhizobium caulinodans, and Bradyrhizobium japonicum. All of the sequences of the fast-growing soybean rhizobia, including strain NGR 234, were identical to the sequence of $R$. meliloti and similar to the sequence of $R$. leguminosarum. These results are discussed in relation to previous findings; we concluded that the fast-growing soybean-nodulating rhizobia belong in the genus Rhizobium and should be called Rhizobium fredii.
\end{abstract}

In 1982 Keyser et al. described fast-growing rhizobia which produced nodules and fixed atmospheric nitrogen on the roots of soybeans and were isolated in the People's Republic of China (15). These bacteria had cultural and physiological properties that were typical of the fast-growing rhizobia classified in the genus Rhizobium $(20,25,33)$, although their host range was similar to that of the slowgrowing species Bradyrhizobium japonicum $(10,25)$. The results of DNA-DNA hybridization studies indicated that the fast-growing soybean-nodulating (FGSN) rhizobia form two closely related groups but exhibit low levels of relationship to the type strains of other rhizobial species (23). Consequently, these organisms were placed in a new species, which was designated Rhizobium fredii (22). The results of serological and phylogenetic studies $(13,19,29)$ indicated that $R$. fredii and Rhizobium meliloti are related.

The work described above was based on 11 strains of fast-growing soybean rhizobia collected in 1982 (15). In 1988 Chen et al. (4) described the results of a numerical taxonomic study involving 9 of the 11 strains that were originally classified as $R$. fredii and 24 additional strains of fastgrowing soybean rhizobia. These organisms were compared with 25 named strains belonging to the genera Rhizobium, Bradyrhizobium, and Agrobacterium. Chen et al. (4) found little relationship between the FGSN rhizobia and the named strains and proposed that $R$. fredii should be reclassified in a new genus, Sinorhizobium.

In this paper we describe partial sequences of $16 \mathrm{~S}$ rRNA genes from representative strains of FGSN rhizobia that were obtained from W. X. Chen and from the U.S. Department of Agriculture. We compared these sequences with sequences from the corresponding regions in $R$. meliloti, Rhizobium leguminosarum, Agrobacterium tumefaciens, Azorhizobium caulinodans, and B. japonicum. Below we also discuss the evidence for and against classification of the FGSN rhizobia in a separate genus, Sinorhizobium; we concluded that this classification is not justified.

\footnotetext{
* Corresponding author.
}

\section{MATERIALS AND METHODS}

Bacterial strains and growth conditions. The strains which we examined are listed in Table 1. The USDA strains were obtained from the U.S. Department of Agriculture Nitrogen Fixation and Soybean Genetics Laboratory, Beltsville, Md. (15); the CCBAU strains were obtained from W. X. Chen, Beijing Agricultural University, Beijing, People's Republic of China (4); and strain NGR 234 was obtained from M. J. Trinick, Commonwealth Scientific and Industrial Research Organisation, Division of Plant Industry, Canberra, Australia (26). The purity of these strains was checked on TY (2) and YMA (27) agar media after incubation for 4 days at $30^{\circ} \mathrm{C}$. DNAs were obtained from cultures grown on TY agar slopes, and cultures were maintained on TY agar slopes at $4^{\circ} \mathrm{C}$.

DNA preparation. DNA was extracted by using a simple procedure involving lysis with sodium dodecyl sulfate, phenol extraction, and ethanol precipitation (34).

DNA amplification and sequencing. Genomic DNA from each strain provided the template from which a 260-bp segment of the 16S rRNA gene was amplified by using the polymerase chain reaction, purified, and sequenced by using the methods and primers (5'-TGGCTCAGAACGAACGCT GGCGGC-3' and 5'-CCCACTGCTGCCTCCCGTAGGAGT$\left.3^{\prime}\right)$ described previously (34).

Nucleotide sequence accession number. The sequence of the type strain of $R$. fredii, strain USDA 205, has been deposited in the GenBank/EMBL data library under accession number M74163.

\section{RESULTS}

16S rRNA sequence data. The sequence data are shown in Fig. 1. The 260-base fragment corresponded to positions 44 to 337 in the Escherichia coli $16 \mathrm{~S}$ rRNA sequence; numbering is in accordance with the overall alignment for the rhizobia (34). The sequences determined for the two chemovars of $R$. fredii, Sinorhizobium fredii, Sinorhizobium xinjiangensis, and strain NGR 234 were identical to the sequence published previously for $R$. meliloti NZP 4017 (34). The corresponding sequence for $R$. leguminosarum 8002 
TABLE 1. List of strains and nomenclature according to Scholla and Elkan and according to Chen et al

\begin{tabular}{|c|c|c|}
\hline Strain & $\begin{array}{c}\text { Chemovar sensu Scholla } \\
\text { and Elkan }{ }^{a}\end{array}$ & $\begin{array}{l}\text { Species sensu } \\
\text { Chen et al. }{ }^{b}\end{array}$ \\
\hline USDA 205 & R. fredii chemovar fredii ${ }^{c}$ & S. fredii ${ }^{c}$ \\
\hline USDA 193 & R. fredii chemovar fredii & S. fredii \\
\hline USDA 201 & R. fredii chemovar siensis ${ }^{c}$ & S. fredii \\
\hline CCBAU 116 & Not studied & S. fredii \\
\hline CCBAU 110 & Not studied & S. xinjiangensis ${ }^{c}$ \\
\hline CCBAU 105 & Not studied & S. xinjiangensis \\
\hline NGR 234 & Not studied & Not studied \\
\hline
\end{tabular}

${ }^{a}$ See reference 22 .

$b$ See reference 4 .

c Type strain of species or chemovar.

(34), which was the same as the sequences for several other $R$. leguminosarum strains, including the type strain (33a), differed from the $R$. fredii sequence at seven nucleotide positions. In contrast, the sequences for strains classified in other genera of the family Rhizobiaceae, including strains of Agrobacterium tumefaciens, Azorhizobium caulinodans, and $B$. japonicum, differed from the $R$ : fredii sequence at 21 , 38 , and 37 nucleotide positions, respectively $(32,34)$.

Phylogenetic relationships. The phylogenetic relationships between $R$. fredii and strains belonging to related bacterial genera are shown in Fig. 2. Figure 2 was constructed by using the neighbor-joining method (21) from a Jukes-Cantor distance matrix that was derived from the sequences in Fig. 1 and the corresponding parts of previously published sequences available from the Genbank/EMBL data library (34). Positions 26 to 41 were omitted because this stem loop varied in length among the sequences that were compared and could not be aligned unambiguously. The partial $16 \mathrm{~S}$ rRNA sequence data which we used yielded a phylogeny for the alpha proteobacteria (34) which was in good agreement with previously described conclusions that were based on the similarities of whole 16S rRNA molecules (31).

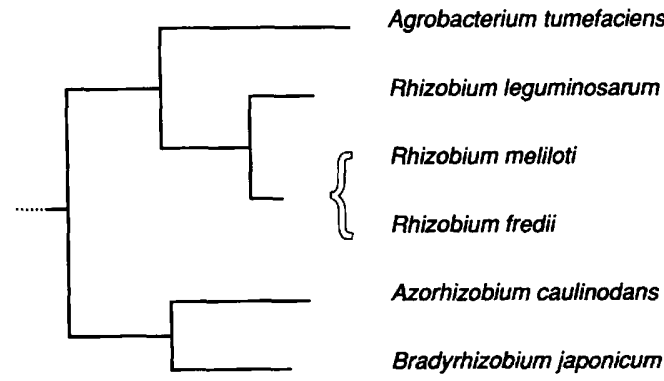

FIG. 2. Phylogenetic tree of species in the Rhizobiaceae constructed by using the neighbor-joining method (21) from JukesCantor distances derived from the sequences in Fig. 1 and rooted by reference to Ehrlichia risticii (30), a distant member of the alpha subgroup of the proteobacteria. The scale bar represents $2 \%$ substitutions.

\section{DISCUSSION}

Taxonomic position of strain NGR 234. Strain NGR 234 was one of the fast-growing tropical rhizobial strains that were isolated by Trinick (26). These organisms had various host ranges and resembled $R$. meliloti in their bacteriological properties. Strain NGR 234 was isolated from Lablab purpureus but was also effective on many other plants, including soybeans. Although this strain has been studied widely (see references 3 and 24 for reviews), it has never been assigned to any formal species. Our 16S rRNA data indicate that it is closely related to $R$. meliloti and the FGSN rhizobia. Young and Johnston (35) pointed out that the nodD gene of strain MP1K3030, a derivative of strain NGR 234 (12), is almost identical to the nodDl gene of strain USDA 191 (1), a representative FGSN strain, and these genes are quite distinct from all of the other nodD genes that have been sequenced so far. Furthermore, strain NGR 234 cross-reacts strongly with antisera prepared against various FGSN rhizo-

10

30

50

70

90

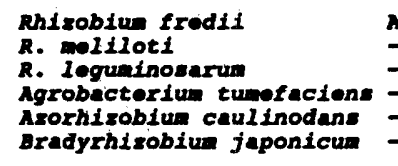

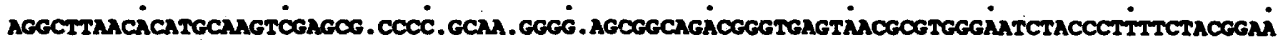

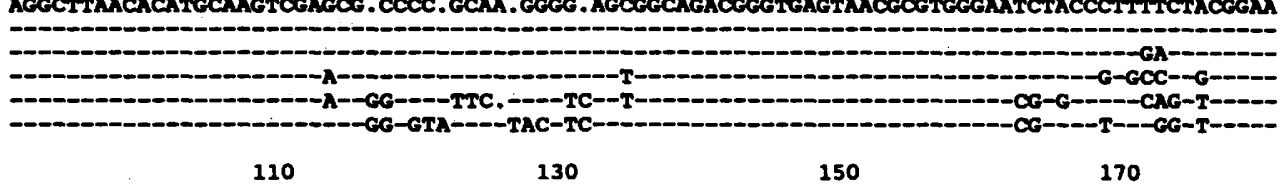

Rhisobiu fredil

R. mliloti

R. leguninosarum

Agrobactorius tubefacion

Azorhisobiu caulinodans

Bradyrhizobium japonicum

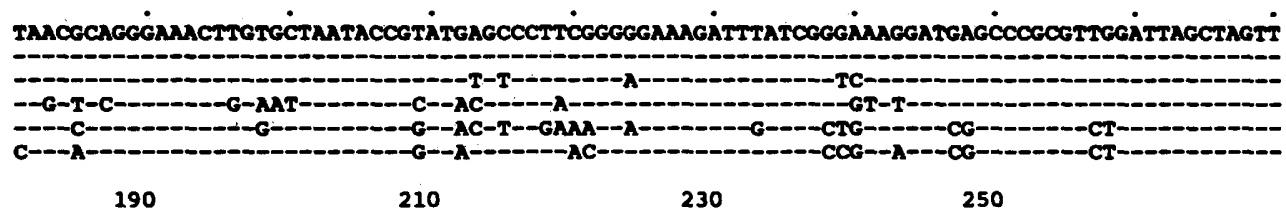

Rhisobiu fredit

R. Dilloti

R. Leguinoserum

Agrobacterium tunofacien

Azorhisobium caulinodan:

Bradyrhisobium japonicum

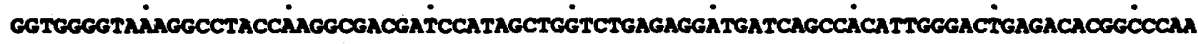

FIG. 1. Sequence of parts of the $16 \mathrm{~S}$ rRNA genes of the type strain of $R$. fredii, strain USDA 205, and six other strains listed in Table 1 (all of the sequences were identical). For comparison the previously published sequences for the following other members of the Rhizobiaceae are also shown: $R$. meliloti NZP 4017 (34), R. leguminosarum biovar phaseoli 8002 (34), Agrobacterium tumefaciens DSM 30105 (32), Azorhizobium caulinodans ORS 571 (34), and $B$. japonicum USDA $110(34)$. The dashes indicate identity with the $R$. fredii sequence, and the dots indicate alignment gaps. 
bia and reacts specifically with antiserum prepared against somatic antigens from the type strain of $R$. fredii, strain USDA 205 (19). Consequently, it seems likely that strain NGR 234 belongs to the same species as the FGSN rhizobia, but a DNA-DNA relatedness study is needed to confirm this.

Taxonomic position of FGSN rhizobia. We reviewed our results in relation to all of the available data in order to determine the taxonomic position of the FGSN rhizobia.

Assessment by DNA relatedness. Scholla et al. (23) determined the levels of DNA relatedness among five strains of FGSN rhizobia and reference strains of $R$. leguminosarum bv. trifolii, $R$. leguminosarum bv. phaseoli, $R$. leguminosarum bv. viciae, $R$. meliloti, "Rhizobium lupini," and $B$. japonicum. These authors found a mean level of relatedness between the fast-growing soybean rhizobia and the reference strains of $20.0 \%$. Chen et al. (4) concluded that the fastgrowing soybean rhizobia should not be classified as Rhizobium or Bradyrhizobium species. Two points should be made here. First, the spectrophotometric hybridization method that was used by Scholla et al. (23) is not accurate at this level of relatedness (9). Second, the range of values which Scholla et al. obtained (5 to $40 \%$ ) indicates that some of the strains may be within the range expected for closely related species (14). Consequently, these values provide no justification for placing the fast-growing soybean rhizobia in a separate genus.

Wedlock and Jarvis (29) compared the original 11 strains of fast-growing soybean rhizobia with representative strains belonging to nine other DNA relatedness groups in the Rhizobiaceae $(6,11,16)$. These authors confirmed that the fast-growing soybean rhizobia constituted a new DNA relatedness group but also found that all strains of $R$. fredii exhibited moderate levels of relatedness (mean, $41.5 \%$; range, 36 to $44 \%$ ) with $R$. meliloti NZP 4009 (= SU47). This indicated that $R$. fredii and $R$. meliloti are closely related species (14).

Assessment by rRNA similarity. Chen et al. (4) overlooked a relevant publication by Jarvis et al. (13), who included two strains of $R$. fredii, strains USDA 191 and USDA 208, in a study of intra- and intergeneric similarities among the rRNA cistrons of strains representing nine DNA relatedness groups within the Rhizobiaceae $(6,11,16)$. Five strains of $R$. meliloti had a mean thermal denaturation value of $81.6^{\circ} \mathrm{C}$ (range, 81.8 to $81.4^{\circ} \mathrm{C}$ ) with rRNA from $R$. meliloti NZP 4009 , and the two strains of $R$. fredii had thermal denaturation values of $81.2^{\circ} \mathrm{C}$ with the same reference rRNA. This result agrees with the DNA relatedness data (29) and indicates that sequence homology was conserved across the whole 23S rRNA cistron in the strains of $R$. meliloti and $R$. fredii examined. This result was independently confirmed by the data in Fig. 1, which shows that we observed no differences among the sequences of a 260 -bp region in the 16S rRNA cistrons from $R$. meliloti and several reference strains which represented the diversity of fast-growing soybean rhizobia examined by Chen et al. (4). However, Fig. 1 and 2 indicate that this method is capable of detecting differences between $R$. meliloti and $R$. leguminosarum (mean difference in thermal denaturation values, $1.7^{\circ} \mathrm{C}$ ) or between $R$. meliloti and an Agrobacterium sp. (mean difference in thermal denaturation values, $\left.2.9^{\circ} \mathrm{C}\right)(13)$. We concluded that phylogenetic data support inclusion of the fastgrowing soybean rhizobia in the genus Rhizobium as a separate species, Rhizobium fredii, and do not support transfer of these organisms to a new genus, Sinorhizobium. This conclusion is also consistent with the results of previ- ously published studies of the organization the nif gene $(1,8$, 17) and with serological data (19).

Assessment by numerical taxonomy. In their phenotypic study Chen et al. (4) examined each strain for 240 characters and presented a dendrogram in which the FGSN rhizobia were in phena I and II, which could be clustered together at a similarity index value of $58.5 \%$. Reference strains of Rhizobium and Bradyrhizobium species were clustered together at a similarity index value of $62.3 \%$. These two groups could be combined at a similarity index value of $50 \%$. Chen et al. concluded that the FGSN rhizobia are sufficiently different to be classified in a separate genus, Sinorhizobium. However, the deeper levels of branching in phenetic dendrograms cannot be taken as an infallible guide to the true relationships between primary clusters. These relationships can be verified only by comparison with the results of another method, such as DNA-DNA or rRNA-DNA hybridization (7). This was illustrated by two recent studies involving numerical taxonomy and root nodule bacteria. In one, Chen et al. (5) used a similarity coefficient and clustering strategy different from the coefficient and strategy used in their previous study (4) and presented a revised dendrogram in which the genus Agrobacterium was outside the Rhizobium cluster and the level of similarity between the genera Rhizobium and Sinorhizobium had increased from 50\% (4) to $70 \%$ (5). In the second study, Zhang et al. (36) compared the rhizobia from tree legumes with named Rhizobium and Bradyrhizobium reference strains. The dendrogram which they presented indicated that $R$. meliloti is less similar to $R$. leguminosarum than to Bradyrhizobium $\mathrm{sp}$. Zhang et al. did not comment on this novel observation except to recommend genomic studies to determine the exact taxonomic position of the leguminous tree rhizobia. Instead, they concentrated on the distribution of the tree legume rhizobia among the primary clusters. We concluded that Chen et al. (4) attached undue significance to the deeper levels of branching in their dendrogram; this alone could not justify the establishment of a new genus of root nodule bacteria.

Taxonomic conclusions. The designation of fast-growing soybean rhizobia as a separate species (22) is supported by the phenotypic differences observed by Chen et al. (4), while the close phylogenetic relationship between these bacteria and $R$. meliloti indicates that both taxa belong to the same genus, Rhizobium. Thus, the name Sinorhizobium is a synonym of the name Rhizobium, and Rhizobium fredii is the correct name for the fast-growing soybean rhizobia. This conclusion is based upon phenetic and phylogenetic results and conforms with the principle that "nomenclature should reflect genomic relationships to the greatest extent possible" $(18,28)$. Judgement should be reserved on $R$. fredii chemovar siensis (22) and the organism currently designated Sinorhizobium xinjiangensis (4) until the existence of these taxa as discrete entities is confirmed by additional phenotypic and DNA relatedness studies, respectively.

\section{ACKNOWLEDGMENTS}

We thank W. X. Chen for providing Sinorhizobium cultures, and B.D.W.J. thanks the Massey University Council for sabbatical leave and the John Innes Institute for providing facilities.

\section{REFERENCES}

1. Appelbaum, E. R., D. V. Thompson, K. Idler, and N. Chartrain. 1988. Rhizobium japonicum USDA 191 has two nodD genes that differ in primary structure and function. J. Bacteriol. 170:12-20.

2. Beringer, J. E. 1974. R-factor transfer in Rhizobium leguminosarum. J. Gen. Microbiol. 84:188-198. 
3. Cervantes, E., J.-C. van Slooten, and J. Stanley. 1991. Rhizobium sp. NGR234: molecular microbial ecology and multiple symbiosis. Symbiosis 8:251-270.

4. Chen, W. X., G. H. Han, and J. L. Li. 1988. Numerical taxonomic study of fast-growing soybean rhizobia and a proposal that Rhizobium fredii be assigned to Sinorhizobium gen. nov. Int. J. Syst. Bacteriol. 38:392-397.

5. Chen, W. X., G. S. Li, Y. L. Qi, E. T. Wang, H. L. Yuan, and J. L. Li. 1991. Rhizobium haukuii sp. nov. isolated from the root nodules of Astragalus sinicus. Int. J. Syst. Bacteriol. 41:275280.

6. Crow, V. L., B. D. W. Jarvis, and R. M. Greenwood. 1981. Deoxyribonucleic acid homologies among acid-producing strains of Rhizobium. Int. J. Syst. Bacteriol. 31:152-172.

7. De Ley, J., W. Mannheim, P. Segers, A. Lievens, M. Denijn, M. Vanhoucke, and M. Gillis. 1987. Ribosomal ribonucleic acid cistron similarities and taxonomic neighborhood of Brucella and CDC group Vd. Int. J. Syst. Bacteriol. 37:35-42.

8. Egelhoff, T. T., R. F. Fisher, T. W. Jacobs, J. T. Mulligan, and S. R. Long. 1985. Nucleotide sequence of Rhizobium meliloti 1021 nodulation genes: nod $D$ is read divergently from nod $A B C$. DNA 4:241-248.

9. Grimont, P. A. D. 1988. Use of DNA reassociation in bacterial classification. Can. J. Microbiol. 34:541-546.

10. Heron, D. S., and S. G. Pueppke. 1984. Mode of infection, nodulation specificity, and indigenous plasmids of 11 fastgrowing Rhizobium japonicum strains. J. Bacteriol. 160:10611066.

11. Hollis, A. B., W. E. Kloos, and G. H. Elkan. 1981. DNA:DNA hybridization studies of Rhizobium japonicum and related Rhizobiaceae. J. Gen. Microbiol. 123:215-222.

12. Horvath, B., C. W. B. Bachem, J. Schell, and A. Kondorosi. 1987. Host-specific regulation of nodulation genes in Rhizobium is mediated by a plant signal interacting with the nodD gene product. EMBO J. 6:841-848.

13. Jarvis, B. D. W., M. Gillis, and J. DeLey. 1986. Intra- and intergeneric similarities between the ribosomal ribonucleic acid cistrons of Rhizobium and Bradyrhizobium species and some related bacteria. Int. J. Syst. Bacteriol. 36:129-138.

14. Johnson, J. L. 1984. Nucleic acids in bacterial classification, p. 8-11. In N. R. Krieg and J. G. Holt (ed.), Bergey's manual of systematic bacteriology, vol. 1. The Williams \& Wilkins Co., Baltimore.

15. Keyser, H. H., T. S. Hu, B. B. Bohlool, and D. F. Weber. 1982. Fast-growing rhizobia isolated from root nodules of soybean. Science 215:1631-1632.

16. Lindstrom, K., B. D. W. Jarvis, P. E. Lindstrom, and J. J. Patel. 1983. DNA homology, phage-typing and cross-nodulation studies of rhizobia infecting Galega species. Can. J. Microbiol. 29:781-789.

17. Masterton, R. V., P. R. Russell, and A. G. Atherly. 1982. Nitrogen fixation (nif) genes and large plasmids of Rhizobium japonicum. J. Bacteriol. 152:928-931.

18. Murray, R. G. E., D. J. Brenner, R. R. Colwell, P. De Vos, M. Goodfellow, P. A. D. Grimont, N. Pfennig, E. Stackebrandt, and G. A. Zavarzin. 1990. Report of the Ad Hoc Committee on Approaches to Taxonomy within the Proteobacteria. Int. J. Syst. Bacteriol. 40:213-215.

19. Sadowsky, M. J., B. B. Bohlool, and H. H. Keyser. 1987. Serological relatedness of Rhizobium fredii to other rhizobia and to the bradyrhizobia. Appl. Environ. Microbiol. 53:1785-1789.

20. Sadowsky, M. J., H. H. Keyser, and B. B. Bohlool. 1983.
Biochemical characterization of fast- and slow-growing rhizobia that nodulate soybeans. Int. J. Syst. Bacteriol. 33:716-722.

21. Saitou, N., and M. Nei. 1987. The neighbour-joining method: a new method for reconstructing phylogenetic trees. Mol. Biol. Evol. 4:406-425.

22. Scholla, M. H., and G. H. Elkan. 1984. Rhizobium fredii sp. nov., a fast-growing species that effectively nodulates soybeans. Int. J. Syst. Bacteriol. 34:484-486.

23. Scholla, M. H., J. A. Moorefield, and G. H. Elkan. 1984. Deoxyribonucleic acid homology between fast-growing soybean-nodulating bacteria and other rhizobia. Int. J. Syst. Bacteriol. 34:283-286.

24. Stanley, J., and E. Cervantes. 1991. Biology and genetics of the broad host range Rhizobium sp. NGR234. J. Appl. Bacteriol. 70:9-19.

25. Stowers, M. D., and A. R. J. Eaglesham. 1984. Physiological and symbiotic characteristics of fast-growing Rhizobium japonicum. Plant Soil 77:3-14

26. Trinick, M. J. 1980 . Relationships amongst the fast-growing rhizobia of Lablab purpureus, Leucaena leucocephala, Mimosa spp., Acacia farnesiana and Sesbania grandiflora and their affinities with other rhizobial groups. J. Appl. Bacteriol. 49:3953.

27. Vincent, J. M. 1970. A manual for the practical study of root nodule bacteria. Blackwell Scientific Publications, Oxford.

28. Wayne, L. G., D. J. Brenner, R. R. Colwell, P. A. D. Grimont, O. Kandler, M. I. Krichevsky, L. H. Moore, W. E. C. Moore, R. G. E. Murray, E. Stackebrandt, M. P. Starr, and H. G. Truper. 1987. Report of the Ad Hoc Committee on the Reconciliation of Approaches to Bacterial Systematics. Int. J. Syst. Bacteriol. 37:463-464

29. Wedlock, D. N., and B. D. W. Jarvis. 1986. DNA homologies between Rhizobium fredii, rhizobia that nodulate Galega sp., and other Rhizobium and Bradyrhizobium species. Int. J. Syst. Bacteriol. 36:550-558.

30. Weisberg, W. G., M. E. Dobson, J. E. Samuel, G. A. Dasch, L. P. Mallavia, O. Baca, L. Mandelco, J. E. Sechrest, E. Weiss, and C. R. Woese. 1989. Phylogenetic diversity of the rickettsiae. J. Bacteriol. 171:4202-4206.

31. Woese, C. R., E. Stackebrandt, W. G. Weisberg, B. J. Paster, M. T. Madigan, V. J. Fowler, C. M. Hahn, P. Blanz, R. Gupta, K. H. Nealson, and G. E. Fox. 1983. The phylogeny of purple bacteria: the alpha sub-division. Syst. Appl. Microbiol. 5:315326.

32. Yang, D. C., Y. Oyaizu, H. Oyaizu, G. J. Olsen, and C. R. Woese. 1985. Mitochondrial origins. Proc. Natl. Acad. Sci. USA 82:4443-4447.

33. Yelton, M. M., S. S. Yang, S. A. Edie, and S. T. Lim. 1983. Characterization of an effective salt-tolerant fast-growing strain of Rhizobium japonicum. J. Gen. Microbiol. 129:1537-1547.

33a.Young, J. P. W., and H. L. Downer. Unpublished data.

34. Young, J. P. W., H. L. Downer, and B. D. Eardly. 1991. Phylogeny of the phototrophic Rhizobium BTail by polymerase chain reaction-based sequencing of a $16 \mathrm{~S}$ rRNA gene segment. J. Bacteriol. 173:2271-2277.

35. Young, J. P. W., and Johnston, A. W. B. 1989. The evolution of specificity in the legume-Rhizobium symbiosis. Trends Ecol. Evol. 4:341-349.

36. Zhang, X.-P., R. Harper, M. Karsisto, and K. Lindstrom. 1991. Diversity of Rhizobium bacteria isolated from the root nodules of leguminous trees. Int. J. Syst. Bacteriol. 41:104-113. 